\title{
A luta pela descolonização e as experiências de alfabetização na Guiné-Bissau: Amilcar Cabral e Paulo Freire
}

\section{The liberation struggle and the experiences of literacy in Guinea-Bissau: Amilcar Cabral and Paulo Freire}

\section{Amilcar Araujo Pereira e Paolo Vittoria}

A luta pela libertação não é apenas um fato cultural mas também um fator de cultura. Amilcar Cabral em Guiné-Bissau, nação africana forjada na luta

Recriar uma sociedade é um esforço político, ético e artístico, é um ato de conhecimento. Trabalho pacientemente impaciente, como diria Amilcar Cabral.

Paulo Freire em Por uma pedagogia da pergunta

\footnotetext{
Amilcar Araujo Pereira é doutor em História pela Universidade Federal Fluminense e professor adjunto na Faculdade de Educação da UFRJ (amilcarpereira@hotmail.com), e Paolo Vittoria é doutor em Pedagogia pela Universidade Federico II de Nápoles, Itália, e professor adjunto da Faculdade de Educação da UFRJ (paolo.vittoria@yahoo.com).

Artigo recebido em 29 de junho e aprovado para publicação em 14 de agosto de 2012.
}

Est. Hist., Rio de Faneiro, vol. 25, no 50, p. 291-311, julho-dezembro de 2012. 


\section{Guiné-Bissau e Amilcar Cabral}

Em um mundo polarizado, em plena "guerra fria", e em um continente repleto de lutas por liberdade, armadas ou não, a autoproclamada, em 24 de setembro de 1973, República da Guiné-Bissau seria, nas palavras de Amilcar Cabral, uma "nação africana forjada na luta" contra o colonialismo português. Situada na costa ocidental da África, entre o Senegal, ao norte, e a Guiné-Conacri, ao sul, segundo o Instituto Nacional de Estatística, a Guiné-Bissau teria atualmente cerca de um milhão e meio de habitantes, ${ }^{1}$ pertencentes a diversos grupos étnicos: balantas, fulas, manjacos, mandingas, papéis, cada qual com sua língua e cultura própria, e dos quais aproximadamente $42,4 \%$ seriam alfabetizados. A obtenção de dados censitários confiáveis sobre a Guiné-Bissau atualmente está bastante difícil, pois a luta pela construção de uma sociedade democrática ainda está em curso naquele país. ${ }^{2}$

Durante cerca de 700 anos, até meados do século XIX, a região que compreende o território da atual Guiné-Bissau fazia parte do reino mandinga de Kaabu, tributário do Império do Mali, que foi "fundado pelo lendário guerreiro mandinga, Sundiata Keita, no século XIII” (Mendy, 2012: 16). Segundo Peter Mendy, até então a influência política do reino de Kaabu se estendia a leste até a região de Casamance, no atual Senegal, ao norte até a atual Gâmbia e ao sul até partes da atual Guiné-Conacri. Na segunda metade do século XIX, ocorreu a desintegração do reino, em função de uma crise política interna e da intensificação da pressão das potências coloniais europeias, especialmente França, Inglaterra e Portugal, que passaram a disputar a domínio sobre o território e a própria demarcação de novas fronteiras.

A presença de navegadores e comerciantes portugueses no litoral da atual Guiné-Bissau remonta a meados do século XV, mas a colonização de fato, a dominação do território, somente se estabeleceu em 1915, através das brutais campanhas de "pacificação", como os portugueses as chamavam, implementadas pelo exército colonial português, que culminaram com o assassinato dos líderes de diferentes grupos étnicos que resistiam à colonização. Mesmo após a dominação do território essas violentas campanhas de "pacificação" permaneceram, ocorrendo até 1936, em função da longa tradição de resistência à colonização portuguesa entre alguns grupos étnicos na Guiné-Bissau. Essa tradição de luta, segundo Amilcar Cabral, teria sido uma fonte de inspiração para a construção da luta de libertação naquele país a partir da década de 1950. (Mendy, 2012: 19) Aliás, o processo de construção da luta de libertação na Guiné-Bissau e em Cabo Verde entre as décadas de 1950 e 1970 se confunde com a própria trajetória política de Amilcar Cabral, até o seu assassinato na Guiné-Conacri em 20 de janeiro de $1973 .{ }^{3}$ 
Nascido em 1924 na região de Bafatá, na Guiné-Bissau, filho de pais caboverdianos, Amilcar Cabral foi a principal liderança na construção do Partido Africano para a Independência da Guiné e Cabo Verde (PAIGC) em setembro de 1956 e na conquista da vitória contra o colonialismo português. ${ }^{4}$ Sua militância intelectual e sua ação prática na liderança do PAIGC o tornaram um símbolo da luta política pela libertação na África. Não era só um revolucionário: era um pedagogo da revolução. Ensinando e aprendendo com seu povo, Cabral foi um dos líderes que conduziu o processo de emancipação através de uma luta política cotidiana. Segundo Carlos Lopes, "Cabral compreendeu que os fundamentos da luta pela libertação nacional eram políticos e, portanto, a vitória só seria possível se os movimentos de libertação conseguissem primeiro articular posições políticas, e só depois justificar a ação militar" (Lopes, 2012: 9).

Após realizar os estudos primários e secundários em Cabo Verde, em 1945 Cabral ganhou uma bolsa de estudos num concurso da "Casa dos Estudantes do Império" e foi estudar no Instituto Superior de Agronomia, em Lisboa, onde se formou agrônomo em 1950. Dois anos após concluir o curso e logo depois de recusar uma vaga de professor assistente no Instituto onde se formara, voltou à sua terra natal contratado pelo Ministério do Ultramar como adjunto dos serviços agrícolas e florestais e, mais importante, como o responsável pela realização do primeiro recenseamento agrícola da Guiné-Bissau. (Fundação Mario Soares, 2000: 79) Essa experiência de contato direto com os camponeses lhe permitiu conhecer como poucos a realidade social, econômica e política em todo o território guineense. A necessidade de conhecer e lidar com a realidade do povo passou a ser uma marca de seu pensamento político. Era da realidade de seu povo que a luta pela libertação deveria partir, pois segundo ele:

(...) o povo não luta por ideias, por coisas que estão na cabeça dos homens. O povo luta e aceita os sacrifícios exigidos pela luta, mas para obter vantagens materiais para poder viver em paz e melhor, para ver sua vida progredir e para garantir o futuro de seus filhos. Libertação nacional, luta contra o colonialismo, construção da paz e do progresso - independência - tudo isso são coisas vazias e sem significado para o povo, se não se traduzem por uma real melhoria das condições de vida (Cabral, 1974a: 46).

Vivendo em Lisboa, entre 1945 e 1952 Cabral foi secretário-geral, presidente do Comitê da Cultura e vice-presidente da "Casa dos Estudantes do Império", onde conviveu com outros estudantes africanos que por lá passavam, como Agostinho Neto, Mario Pinto de Andrade e Eduardo Mondlane, entre outros. ${ }^{5}$ 
Essa experiência internacional e a convivência com outros jovens intelectuais africanos teria sido fundamental para a sua formação e para a construção de sua estratégia política colocada em prática após seu retorno à Guiné-Bissau. Ao fundar o PAIGC, juntamente com outros militantes, Cabral adotou o lema "Unidade e Luta" para o partido. A questão da unidade era fundamental num partido que reunia pessoas de diferentes grupos étnicos, com línguas e culturas distintas, como disse Cabral em um seminário de formação de quadros do PAIGC em 1969: "O significado de nossa luta, não é só em relação ao colonialismo, é também em relação a nós mesmos. Unidade e luta. Unidade para lutarmos contra o colonialista e luta para realizarmos a nossa unidade, para construirmos a nossa terra como deve ser" (Cabral, 1974b: 7).

A adoção dessa estratégia de busca de unidade para lutar contra o colonizador em várias esferas acabou sendo um importante elemento que tornou a luta de libertação na Guiné a mais bem-sucedida entre os países então colonizados por Portugal. Guiné-Bissau foi o primeiro país colonizado por Portugal na África a se autoproclamar independente, ainda em 1973, e a conseguir o reconhecimento de Portugal, um ano depois. As independências de Angola, Moçambique, São Tomé e Príncipe e Cabo Verde somente foram reconhecidas em 1975. Amilcar Cabral também buscava a unidade entre as diferentes organizações em luta contra o colonialismo na África, especialmente o português. Segundo Carlos Lopes, em dezembro de 1956 Cabral teria participado em Luanda da fundação do Movimento Popular para a Libertação de Angola (MPLA), assim como teria sido um dos protagonistas em diversas outras tentativas de se construir organizações de luta pela independência articulando os países colonizados por Portugal na África (Lopes, 2012: 9).

Embora respeitasse e valorizasse aspectos das diferentes culturas dos grupos étnicos que formavam o "povo" guineense, Cabral era defensor de uma unidade em torno da identidade africana, que deveria se sobrepor às divisões étnicas. Essa identidade africana seria um dos produtos da luta de libertação que, segundo ele, não seria apenas um "fato cultural mas também um fator de cultura" (Cabral, 1974a: p.137). Essa luta de libertação, e a descolonização no sentido mais amplo, se dava também através da educação do "povo africano da Guiné e Cabo Verde". Para tanto, centenas de "escolas piloto" foram criadas pelo PAIGC por todo o território libertado da Guiné. Ainda em meio à luta armada, em entrevista concedida em 1969, Cabral dizia o seguinte:

Um homem novo nasce na nossa terra, e se tiver ocasião de falar com as nossas crianças poderá ver que as crianças das nossas escolas têm já uma consciência política, patriótica e que querem lutar pela independência do seu país. Uma consciência que faz com que se enten- 
dam uns com os outros, um sentimento de unidade nacional e de unidade no plano africano (Cabral, 1974a: 71).

Em seu discurso na Assembleia Geral das Nações Unidas, em outubro de 1972, Cabral se dizia orgulhoso da transformação pela qual passava sua terra em função das conquistas obtidas na luta até então: "Estamos orgulhosos, sim, da consciência nacional das nossas populações, da unidade do povo forjada na luta, do desabrochar simultâneo das culturas dos diversos grupos étnicos, das escolas, dos (...) milhares de adultos alfabetizados (...)" (Idem, ib., p.151) As escolas e a alfabetização dos homens e mulheres de Guiné-Bissau eram motivo de orgulho devido ao valor estratégico da educação na luta de libertação. Da mesma forma, a importância dada à questão da história e das culturas africanas para a luta contra o colonialismo é evidente no pensamento de Amilcar Cabral:

Quando a dominação colonial se impõe dentro duma terra a primeira preocupação dessa dominação é barrar o caminho à cultura desse povo. Por isso mesmo consideramos (e isso verificou-se, por exemplo, no processo de desenvolvimento de nacionalismo em África, quando se começaram a cultivar poemas e danças africanas para contestar a cultura do país dominador) que o nosso povo, ao pegar em armas para se bater pela sua libertação, estava em primeiro lugar manifestando a sua recusa em aceitar uma cultura estrangeira. Portanto, essa luta é necessariamente um ato cultural, ato cultural que implica essa conclusão, demonstração clara de que temos uma história nossa na qual fomos retirados pelo colonialismo, e estamos decididos a continuar essa história (Idem, ib., p.115).

Cabral também enxergava a luta contra o racismo - racismo que era uma marca profunda do colonialismo português - como um outro fator de unidade. Como lembrou em entrevista concedida em 1971, "Salazar" chegou a afirmar: 'a África não existe!' Isto é o cúmulo do racismo” (Idem, ib., p. 120). O colonialismo português na África se intensificou no final do século XIX, especialmente após a Conferência de Berlim (1884-1885), onde foi discutida a ocupação da África pelas potências coloniais. A partir de 1892, quando o governo português promulgou a nova pauta aduaneira colonial, na qual "as exportações de Portugal para as colônias africanas passaram a pagar [apenas] entre $10 \% \mathrm{e}$ 20\% dos direitos estabelecidos na pauta geral" (Lains, 1998: 476), segundo vários autores, as políticas de expansão colonial na África traduziram-se num importante benefício financeiro para Portugal. A exploração colonial na África se 
acentuou com a criação da República portuguesa em 1910 e especialmente a partir da implantação da ditadura militar em 1926 e do regime do Estado Novo em 1933. A violência do colonialismo português, muito influenciada pelo racismo de que falava Amilcar Cabral no trecho citado acima, aumentou sobremaneira com a chegada de Antônio Salazar ao poder e com a implementação do Acto Colonial de 1930,

o qual foi depois introduzido como apêndice à Constituição de 1933, estipulou-se no artigo $20^{\circ}$ que o Estado tinha a faculdade de obrigar os indígenas a trabalhar em obras públicas de interesse geral para a comunidade, em ocupações cujo resultado lhes pertencesse, na execução de decisões judiciárias penais, ou no cumprimento de obrigações fiscais. Por outras palavras, reintroduzia-se um sistema de trabalho semiescravo, cujos principais beneficiários iam ser aquelas companhias que necessitavam de infraestruturas, meios de comunicação e outras, para levarem a cabo as suas atividades econômicas (Rato, 1983: 1128).

O regime fascista de Salazar tratou de reprimir qualquer possibilidade de revolta dos africanos e, logo em 1932, criou a PIDE (Polícia Internacional para a Defesa do Estado), que em última instância foi a responsável pelo assassinato de diversos líderes africanos, entre eles Amilcar Cabral. O mesmo regime fascista que agia com violência na repressão a manifestações de opositores no território português assassinava africanos, como no conhecido caso do "massacre de Pidjiguiti", ocorrido em 3 de agosto de 1959, quando mais de 50 estivadores e marinheiros em greve foram assassinados e centenas ficaram feridos por tiros disparados pelo exército colonial português. Até esse massacre em Pidjguiti o PAIGC articulava a luta política pela libertação na Guiné-Bissau através de greves e manifestações pacíficas. Mas o evento em 1959 no porto de Pidjguiti foi um divisor de águas: ali o PAIGC decidiu começar a organizar a luta armada no campo, que seria implementada a partir de 23 de janeiro de 1963 com o ataque à guarnição portuguesa em Tite, no sul da Guiné-Bissau.

Segundo Clarence-Smith, durante os anos 1930 as colônias teriam sido importantes para a consolidação do novo regime de Salazar. Contudo, nas décadas de 1960 e 70, o governo português teria combatido os movimentos de libertação na África "mais para preservar o regime do que para salvar a economia." (Clarence-Smith apud Lains, 1998: 466). Ainda em 1962, Amilcar Cabral previu a queda do regime fascista em função da vitória das lutas de libertação na África, o que aconteceria em Portugal com a Revolução dos cravos, em 25 de abril de 1974. Em sua análise sobre o fascismo português, Cabral dizia o seguinte: "Se a 
queda do fascismo em Portugal poderia não conduzir ao fim do colonialismo português - sendo, aliás, esta hipótese proclamada por alguns dirigentes da oposição portuguesa - estamos seguros de que a liquidação do colonialismo português arrastará a destruição do fascismo em Portugal" (Cabral, 1974a: 17).

É importante ressaltar sua capacidade de análise política e seu caráter diplomático. Um bom exemplo nesse sentido é a recorrente afirmação de que a luta do PAIGC era contra o colonialismo português e não contra o povo de Portugal:

Nós nunca confundimos "colonialismo português" com "povo de Portugal" e temos feito tudo, na medida das nossas possibilidades, para preservar, apesar dos crimes cometidos pelos colonialistas portugueses, as possibilidades de uma cooperação, de amizade, de solidariedade e de colaboração eficaz com o povo de Portugal, numa base de independência, de igualdade de direitos e de reciprocidade de vantagens, seja para o progresso da nossa terra, seja para o progresso do povo português (Cabral, 1974a: 18).

Através de sua busca pela participação nos vários fóruns internacionais, Cabral conseguiu angariar apoio, para a luta de libertação na Guiné-Bissau, de países do bloco socialista como a China e de países capitalistas como a Suécia. Com uma postura diplomática, informada pelo que chamamos de um "pragmatismo revolucionário" - partindo sempre da realidade de seu povo e lutando de diferentes formas para construir as condições necessárias para a libertação-, Cabral circulava nos mais diversos lugares. Por exemplo, em fevereiro de 1970 ele fez um discurso em Washington perante a Comissão de Relações Exteriores do Congresso norte-americano, e em abril participou das celebrações pelo centenário do nascimento de Lênin em Moscou. No dia 1 de julho daquele ano o Papa Paulo VI o recebeu no Vaticano, juntamente com Marcelino dos Santos e Agostinho Neto, líderes das lutas de libertação em Moçambique e Angola, respectivamente. Tratava-se de uma importante vitória diplomática, pois a partir daquele momento Portugal, um país majoritariamente católico, passaria a ter de lidar com o fato de que o Sumo Pontífice havia recebido em audiência os principais líderes em luta contra o colonialismo português na África.

No ano de 1972, em outubro, Cabral discursou perante a IV Comissão da Assembleia Geral das Nações Unidas em Nova Iorque e recebeu o título de doutor honoris causa da Lincoln University na Pensilvânia, nos Estados Unidos; em dezembro, viajou para Moscou, onde recebeu o mesmo título de doutor honoris causa da Academia de Ciências da URSS, fato bastante incomum durante a 
"guerra fria". A reportagem do jornal The New York Times de 28/1/1973, que repercutia a morte Cabral e o apresentava como um "Símbolo da esperança" e "um dos mais originais pensadores políticos e estrategistas militares", pode ser um bom exemplo da amplitude alcançada por esse "simples africano", como ele costumava se autoidentificar. Além de viajar pelo mundo buscando apoio para a luta contra o colonialismo português na África, Cabral também publicou textos que se tornaram importantes referências para a luta contra o colonialismo e o racismo nos Estados Unidos, no Brasil e em vários outros países.

Logo após o seu assassinato, tanto o The New York Times quanto o The Washington Post do dia 22/1/1973 afirmavam que Amilcar Cabral era "considerado o mais brilhante e bem-sucedido líder" da luta por idependência nos países africanos então colonizados por Portugal. A influência exercida pela figura de Amilcar Cabral entre os militantes do movimento negro, que se organizava politicamente em meados da década de 1970 no Brasil, pode ser observada no trecho da entrevista de Amauri Mendes Pereira, ${ }^{7}$ em que ele relata uma das formas de ação levadas a cabo pelos ativistas negros brasileiros durante o período da ditadura militar (1964-1985):

Outra ação que a gente fazia era entrar, por exemplo, na Associação Brasileira de Imprensa, ABI. Naquele período da luta contra a ditadura, da resistência democrática, os jornalistas se reuniam na ABI. (...) E a gente ia lá. Fazer o quê? Gritar. Em dado momento a gente ia entrando pelo plenário. Não podia, mas a gente falava: "Por que não pode? Nós somos negros e temos direito. Aí não tem negro!” Num momento que a gente achava melhor, invadia, ia entrando. E aí pausadamente, porque eu tinha sempre na minha cabeça o Amilcar Cabral em Havana. Imagina: Ho Chi Min, Fidel, Sukarno, os que fizeram as revoluções no mundo inteiro estavam em 1966 na Tricontinental de Havana. ${ }^{8}$ Todo mundo ia lá e falava: "O imperialismo...!" O Amilcar Cabral, com seu um metro e cinquenta e poucos, vinha andando serenamente - na minha mente, não tem filme sobre isso -, chegava no palco e dizia o discurso dele escrito, que eu tinha decorado: "Não viemos aqui nos pegar contra o imperialismo. Isso nós fazemos de arma na mão na nossa terra. Nós viemos aqui mostrar para vocês a importância da arma da teoria." Para mim isso era o máximo.

A influência no Brasil do pensamento e das ações de Amilcar Cabral e da experiência da luta contra o colonialismo na África não se restringiu ao movimento negro, como se verá abaixo. 


\section{A influência de Amilcar Cabral em Paulo Freire 9}

A trajetória política de Amilcar Cabral teve uma importante presença no pensamento do educador brasileiro Paulo Freire (1921-1997). Freire não conheceu pessoalmente Cabral, mas se inspirou em seus pensamentos e em sua ação política para repensar os caminhos da educação libertadora, e dedicou a ele seu livro Cartas à Guiné-Bissau, onde o define como "educador educando do seu povo" (Freire, [1977] 1984). Nesse livro, Freire reflete sobre as experiências de alfabetização que coordenou na Guiné-Bissau em 1974 e que marcaram profundamente suas práticas e reflexões. A educação, como o próprio Freire ressaltou, não é um processo neutro, mas um ato político. Nessa "politicidade da educação", como ele costumava dizer, se encontra sua intencionalidade de libertação dos povos oprimidos e de construção de uma sociedade "menos injusta, menos feia e menos malvada". A alfabetização, nessa perspectiva, não é uma simples técnica, mas um processo de descolonização cultural. Isso foi muito claro, tanto na Guiné-Bissau quanto nos primeiros passos em articulação com os movimentos de base que surgiam, especialmente no nordeste e no norte do Brasil, no início da década de 1960.

Lembramos, por exemplo, da experiência de Angicos em 1962-63 em que, através de um sistema revolucionário de alfabetização, baseado na pesquisa do universo vocabular, nos círculos de cultura, nas palavras geradoras - em suma, numa filosofia inspirada no diálogo e na valorização da cultura popular -, cerca de 300 trabalhadores rurais e urbanos aprenderam a ler e escrever em apenas 45 dias. Se a experiência de Angicos chamou a atenção a ponto de Freire ser convidado, em janeiro de 1964, pelo então presidente João Goulart para coordenar o plano nacional de alfabetização, quando, três meses depois, houve o golpe militar, essa experiência criou suspeita e perseguição. Freire era na época um jovem intelectual formado em Direito, mas que abraçou logo o mundo da educação. Desde 1960 estava engajado no Movimento de Cultura Popular de Pernambuco e atuava na livre-docência de História e Filosofia na Universidade do Recife (atual Universidade Federal de Pernambuco). Sua longa trajetória no Serviço Social das Indústrias (1949-1959) fez dele um educador que aprendia com as práticas, tomando consciência dos limites da pedagogia tradicional na educação dos trabalhadores.

Desde os primeiros passos, Freire pensava a educação como prática de liberdade e, em consequência, de descolonização. Isso é muito claro nas suas duas primeiras grandes publicações, A educação como prática da liberdade ([1967] 2005) e Pedagogia do oprimido ([1970] 2006), e, em sentido amplo, em toda sua trajetória de vida. Sua presença na Guiné-Bissau em 1974 foi crucial porque lhe deu a possibilidade de se confrontar mais de perto com as contradições do processo 
colonial, num momento em que, enfim, se abriam os horizontes da libertação e da independência naquele país.

Exilado em 1964 por causa das contínuas pressões do governo militar, Paulo Freire atravessou vários países: passou pela Bolívia e pelo Chile, onde se estabeleceu por cinco anos, coordenando um plano de alfabetização. $\mathrm{O}$ Chile recebeu o prêmio da Unesco por ser um dos países a ter enfrentado de maneira mais eficiente o problema do analfabetismo naquele período. Após ter mudado sua relação com o governo chileno, Freire foi para os Estados Unidos, para a Universidade de Harvard, onde começou a divulgar sua teoria da educação e do conhecimento. Depois de um ano nos EUA, insatisfeito com a ideia de uma carreira meramente acadêmica, assim como Cabral recusara o cargo de professor universitário em Lisboa em 1952 para seguir para a Guiné-Bissau e atuar junto à população camponesa, Freire aceitou o convite do Conselho Mundial das Igrejas, instituição interecumênica fundada em 1948, com sede em Genebra (Suíça), ${ }^{10}$ com o objetivo de realizar um trabalho com o povo, de ser um educador "na esquina da rua", como ele amava dizer.

Profundamente religioso e politicamente radical, Freire se moveu com plena autonomia em um contexto ecumênico. De fato, ao longo de sua vida, o cristianismo de base teve um papel de fundamental importância, tanto pela construção dos significados de justiça e de defesa das classes menos favorecidas, como pela formação de um sentimento de indignação. As leituras políticas de inspiração marxista, por outro lado, o ajudaram a compreender a complexidade das dinâmicas econômicas e sociais que determinam estas condições de opressão. Ele nunca considerou incompatíveis as duas perspectivas, como ele mesmo testemunhou:

Eu fui, na minha juventude, ao camponês e ao operário da minha cidade, movido pela opção cristã. Que eu não renego. Chegando lá, a dramaticidade existencial dos homens e das mulheres com que eu comecei a dialogar me remeteu a Marx. É como se os camponeses me tivessem dito: olha, Paulo, vem cá, você conhece Marx? Eu fui a Marx por isso (Apoluceno de Oliveira, 2003: 32-33).

Em Genebra, enquanto trabalhava no Conselho Mundial, Freire fundou o IDAC (Instituto de Ação Cultural), grupo que desenvolvia projetos relacionados à marginalização, à questão de gênero, à condição da classe operária e à escola pública. Foi através do IDAC e do Conselho Mundial que desenvolveu projetos em países da África ocidental que estavam a caminho da libertação da colonização portuguesa, entre eles Guiné-Bissau e Cabo Verde, depois de ter já 
passado pela Zâmbia e pela Tanzânia, onde se articulou com vários grupos engajados em movimentos de libertação. Como vimos acima, o governo da Guiné tinha sido constituído recentemente, com a independência em 1973, e a presença de Freire no país, naquele contexto, foi de profunda importância para ele, pela oportunidade de conviver e trocar ideias com um movimento de libertação do colonialismo português que apresentava elementos de forte consonância com seu pensamento e sua prática político-educativa.

\section{Freire, Cabral e a pedagogia da práxis}

Como vários autores ressaltam (Scocuglia, 2010; Gadotti, 2010), a experiência de Paulo Freire na África foi de profunda importância porque, atrelando o processo educativo ao sistema de produção material e cultural, ele radicalizou alguns princípios da sua teoria da educação. Além da vinculação entre produção e educação, que, como veremos depois, emerge claramente nos Cadernos de Cultura Popular, radicalizou-se o princípio da educação como luta de descolonização através da união entre teoria e prática.

Freire percebeu com clareza e precisão a presença da práxis revolucionária em Amilcar Cabral. É nessa práxis, ou seja, na relação dialética entre ação e reflexão para a transformação da sociedade, que o educador pernambucano ressalta um elemento fundamental da "pedagogia da revolução" de Amilcar Cabral. A práxis se estende na dimensão pedagógica quando abrange a capacidade de ensinar a aprender através da luta de libertação e da comunhão com o próprio povo. Lemos nas Cartas à Guiné-Bissau:

Denúncia e anúncio jamais estiveram, em Amilcar Cabral, dissociados, como também jamais fora da práxis revolucionária. A denúncia da realidade opressora, da espoliação, da farsa colonialista que procurava mascarar aquela espoliação, bem como o anúncio da nova sociedade, constituindo-se no meio da velha, através da sociedade revolucionária, ele sempre fez com seus camaradas, na prática de luta. Enquanto um homem que viveu plenamente a coerência entre sua opção política e sua prática, a palavra em Cabral era sempre a unidade dialética entre ação e reflexão, prática e teoria (Freire, 1984: 23).

A práxis é um conceito central na filosofia de Paulo Freire. Insatisfeito com um excesso de abstração que, no final das contas, acaba contribuindo para um espontaneísmo sem orientação, o educador pernambucano insistiu repetida- 
mente na necessária união entre teoria e prática: a teoria é reflexão crítica sobre a prática e é indispensável para voltar à prática com mais consciência. A prática reorienta a teoria e a coloca em discussão. Provavelmente, inspirado na análise da práxis de Marx em $A$ ideologia alemã, Freire considera a dialética entre ação e reflexão um elemento imprescindível para a transformação revolucionária.

A práxis revolucionária envolve a questão do sistema de produção e da descolonização cultural. Nessa relação entre educação e práxis para a transformação dos modos de produção podemos ver espaços cruciais da radicalização da filosofia educacional de Paulo Freire ampliada pela leitura que ele fez de Amilcar Cabral.

\section{Educação e sistema de produção}

A partir dessas premissas, o desafio do programa de alfabetização na Guiné-Bissau recém-libertada consistia na inversão dos moldes da educação colonial para a educação de um povo ativo em sua luta por uma consciência política, mas que tinha um índice altíssimo de analfabetismo: 90\%. (Freire, 1984: 17) Foi a partir dessa experiência de alfabetização que Freire declarou mais vezes inspirar-se politicamente no pensamento de Amilcar Cabral, como lembra também Lutgardes Freire, um dos cinco filhos de Paulo, numa recente entrevista:

O governo da Guiné-Bissau não era antagônico ao plano de alfabetização que meu pai desenvolveu naquele país. Não estava em contradição com suas ideias, ao contrário do que tinha acontecido no Brasil em 1964, depois do golpe de Estado. Assim, foi um trabalho que ele desenvolveu com grande harmonia e liberdade, mas que foi, evidentemente, sério e persistente. (...) Creio que em suas experiências africanas o fundamental foi conhecer a obra do grande revolucionário Amilcar Cabral, que papai continuará a citar mesmo depois de seu retorno ao Brasil. Realmente as ideias de papai tinham grande concordância com as propostas políticas e revolucionárias de Cabral (Vittoria, 2011: 86).

Freire admirava em Cabral também sua influência marxista, desligada de qualquer ortodoxia política, mas profundamente calada no contexto africano, como ele diz nesta palestra:

Amilcar foi, para mim, um muito bom marxista, que fez uma leitura africana de Marx, não uma leitura alemã de Marx, nem uma 
leitura no século passado [XIX]. Ele fez uma leitura deste século [XX] na África. Não é por outra coisa que, no sério discurso que ele fez em Havana, ${ }^{11}$ ele rejeita a afirmação de que a luta de classes é o motor da história. Ele negou isso em Cuba, e diz no texto que não é propriamente a luta de classes; ele analisa historicamente o surgimento das classes, marxistamente falando, e afirma que, muito mais do que a classe, é o modo de produção que se constitui em motor da história (Freire, A. M., 2005:113).

Emerge, nestas palavras, como o pensamento de Freire se refere de uma maneira mais clara e decisiva ao modo de produção. A luta de classes não é vista de modo abstrato, como muitas vezes foi feito numa degeneração do marxismo, mas como parte integrante do processo de produção (elemento original do pensamento de Marx). Nossa opinião é que nesta citação, Freire, mais do que negar a luta de classes, estaria antepondo o modo de produção à luta de classes. O que importa é mudar o modo de produção, sem o qual a luta de classes não teria sentido. Isso não seria possível sem o auxílio da educação. Aqui emerge a relação entre educação e modo de produção. Relação que se estende nos Cadernos de Cultura Popular ${ }^{12}$ redigidos durante a experiência de alfabetização em São Tomé e Príncipe: temas inerentes ao trabalho, à saúde, à higiene faziam parte de um sistema integrado de educação, onde a alfabetização era um pilar fundamental. A diversificação e a expansão do trabalho coletivo no campo constituíam uma valorização das áreas do conhecimento e das habilidades práticas: aprender como fazer melhor uso de sementes e fertilizantes, por exemplo, ou como monitorar as condições do solo e da água para planejar a venda do produto, integrava o programa de alfabetização e de educação em geral. Educação já não era considerada uma atividade especializada, desligada da vida e da produção, mas se tornava função do ambiente social e ferramenta de transformação. O objetivo era que, na realidade em que a alfabetização se tornava possível e útil, se pudesse estabelecer com precisão, através da capacidade criativa e deliberativa do povo, uma influência ativa da comunidade no ambiente social, o que significa ação cultural.

\section{Educação e descolonização}

Freire já tinha apresentado importantes referências da literatura anticolonialista na Pedagogia do oprimido, onde ele citou repetidamente autores como Frantz Fanon e Albert Memmi. Nesta obra ele analisa a relação entre oprimido e opressor, pela qual o oprimido interiorizaria a projeção do opressor, vivendo em 
si a dualidade de ser oprimido e opressor ao mesmo tempo. Esta perspectiva é sem dúvida inspirada pelo Retrato do colonizado precedido do retrato do colonizador, de Memmi ([1957] 2007). A interiorização do opressor e seus mitos seria uma das razões pelas quais a primeira e falsa ideia de libertação do oprimido seria identificar-se com o opressor. Esta dualidade criaria medo da liberdade e abrigo numa realidade fictícia, quando não é possível transformar uma realidade concreta com uma imaginária. O primeiro passo para uma luta de libertação do oprimido seria então reconhecer e superar a dualidade oprimido-opressor no oprimido. Um reconhecimento doloroso, mas necessário.

Influenciado por Amilcar, Paulo Freire questiona a relação entre colonizados e colonizadores nos demais elementos de produção, observando a imposição cultural que acompanhou à época e as estratégias de colonização. Ele denuncia como a cidade do colonizado, aos poucos, se torna cidade colonial. A cidade do colonizador se transforma na "metrópole" que impõe os costumes à cidade colonial e desfruta dos seus bens. Citando novamente Cabral, ele almeja uma "reafricanização" das mentalidades, assim como lemos nas Cartas à Guiné-Bissau:

A história dos colonizados "começava" com a chegada dos colonizadores, com sua presença "civilizatória"; a cultura dos colonizados, expressão da sua forma bárbara de compreender o mundo. Cultura, só a dos colonizadores. A música dos colonizados, seu ritmo, sua dança, seus bailes, a ligeireza do movimento de seu corpo, sua criatividade em geral, nada disto tinha valor. Tudo isto, quase sempre, tinha de ser reprimido e, em seu lugar, imposto o gosto da Metrópole, no fundo, o gosto das classes dominantes.

Por tudo isto é que, para os colonizados que passaram pela alienante experiência da educação colonial, a "positividade" desta educação ou de alguns de seus aspectos só existe quando, independentizando-se, a rejeitam e a superam. Quando, assumindo com seu povo, a sua história, se inserem no processo de "descolonização das mentes", a que faz referência Aristides Pereira; processo que se alonga no que Amilcar Cabral chamava de "reafricanização das mentalidades".

(Freire, 1984: 20)

Continuando nossa leitura veremos como, para a "descolonização das mentes" e a "reafricanização das mentalidades", se fazia necessário reformar o sistema infraestrutural de produção do qual faz parte a educação. 
E isto implica a transformação radical do sistema educacional herdado do colonizador [...] Daí que a transformação radical do sistema educacional herdado do colonizador exija um esforço interestrutural, quer dizer, um trabalho de transformação ao nível de infraestrutura e uma ação simultânea ao nível de ideologia (Idem, ib.).

A questão do programa de alfabetização na Guiné-Bissau era superar a hereditariedade colonial e criar um sistema educativo que deveria, inevitavelmente, relacionar-se à história de um povo colonizado que estava num processo de independência. Nasceu sobre os vestígios do percurso político de mais de uma década de lutas para se libertar do colonialismo, na plena consciência de que isso não era possível sem uma transformação do modo de produção.

\section{O problema da lingua: crioulo ou português?}

Entretanto, um motivo de divergência de opinião entre Paulo Freire e o governo da Guiné-Bissau referia-se ao idioma adotado para as campanhas de alfabetização naquele país. O governo revolucionário decretou que a alfabetização fosse em português, enquanto Freire considerava mais coerente fazê-la em crioulo. Foi o próprio Freire quem denunciou esta contradição:

Nos círculos de cultura tornou-se evidente que os progressos em português, que era a língua oficial do país e das suas escolas, como língua do programa de alfabetização eram extremamente lentos. Esta lentidão deixava claro que o português era completamente alheio às práticas sociais diárias do vilarejo. Os vilarejos não conheciam o português, mesmo na sua forma oral. Os grupos étnicos falam sua língua nativa africana e muitas pessoas, mas não todas, falam crioulo. Esta língua, uma forma de dialeto derivado do português e enriquecido pelas linguagens tradicionais africanas, tornou-se difundida na Guiné-Bissau durante a luta de libertação nacional, quando, justamente, assumiu o papel de língua oral entre os grupos étnicos. Por isso, hoje é considerada a língua nacional do país. Para os camponeses, por outro lado, é meramente uma língua estrangeira que não conhecem (apud IDAC, 1979: 42).

Todavia, devemos considerar também que o crioulo era somente um dos idiomas falados na Guiné-Bissau e que a escolha dessa língua, derivada do português, em detrimento das outras línguas africanas, poderia implicar uma "injusti- 
ça". Mas por que o governo do PAIGC, que lutou por décadas pela independência, teria decidido que a língua das campanhas de alfabetização fosse aquela dos colonizadores? Informado pelo que chamamos aqui de um "pragmatismo revolucionário", Amilcar Cabral já trabalhava com a alfabetização em língua portuguesa nas "escolas-piloto" criadas durante a luta de libertação na primeira metade da década de 1960. Essa escolha se deu possivelmente por uma série de questões bastante práticas: a luta por unidade, lema do próprio partido, como foi visto acima, tornava quase impossível a escolha de uma das línguas nativas africanas faladas no país, pois isso geraria conflito com os outros grupos étnicos; o crioulo, como o próprio Freire percebia, para muitos guineenses não passava de outra língua estrangeira, assim como o português; o português como língua oficial poderia facilitar uma série de questões no processo de construção da República da Guiné-Bissau. Cabral esperava, tendo o Brasil como exemplo, manter boas relações com o povo português. Essa proximidade, que também tem relação com a própria história dos dois países nos últimos séculos, poderia contribuir para a obtenção de apoio nas diversas áreas, na economia, saúde, educação etc., que seriam importantes para a construção de um Estado que pudesse oferecer melhores condições de vida para a população guineense. Além disso, a quantidade de recursos financeiros necessários para a tradução de livros, cartilhas e todos os demais materiais educativos para o crioulo, por exemplo, seria enorme Certamente a questão do idioma escolhido para a alfabetização representou uma profunda contradição e pode ser ainda um interessante objeto de discussão e debate. O fato, como dissemos no início do artigo, é que somente cerca de $42,4 \%$ da população é alfabetizada atualmente. Antes de 1974 o analfabetismo alcançava $90 \%$ da população.

\section{Considerações finais}

Podemos considerar o fator cultural como um profundo elemento de convergência entre Amilcar Cabral e Paulo Freire. Freire ressalta a cultura como um elemento fundamental para a construção do processo de libertação e chega a comparar a sensibilidade de Amilcar Cabral para com a cultura com a de Antonio Gramsci, sugerindo a leitura dos textos de Gramsci e Cabral para a formação dos educadores:

Mas o que acho é o seguinte, um homem como esse [Amilcar Cabral] deveria ser estudado ao lado de um outro, para mim extraordinário, que é o Gramsci. Eu não tenho nenhuma notícia de que o Amilcar estudou Gramsci (...) Agora você veja como ambos se sensibi- 
lizam diante da cultura, sem contudo nem um nem outro hipertrofiarem a cultura (...) Eu tenho uma convicção de que o estudo, o estudo isolado ou simultâneo de textos deles dois, tem uma importância enorme, deve ser feito por educadores. Eu acho que uma das coisas que está fazendo falta aos educadores é exatamente essa compreensão da politicidade da educação e da pedagogia (apud Freire, A. M., 2005: 113).

Quando falamos da cultura, não a consideramos em sentido vago, mas como cultura do povo, ou cultura popular. A cultura do povo é a base necessária para a construção da luta pela libertação: isso é muito claro na trajetória de Amilcar Cabral. Assim como é claro que a própria luta que se realiza como ato cultural também produz cultura. Mas é o próprio povo que dá as ferramentas para esta luta. Caso contrário, seria luta pelo povo e não luta do povo. A valorização da cultura popular foi um dos argumentos constantes nas experiências e nas teorias de Paulo Freire. Sua participação no Movimento de Cultura Popular de Pernambuco foi uma fase crucial nesse sentido. Mas podemos ver na sua própria prática de alfabetização uma estratégia de luta que repensa a cultura a partir da linguagem popular.

Com o elemento da cultura popular se atrela um outro fator de convergência, ou seja, o compromisso de Cabral e Freire com os trabalhadores urbanos e rurais. Cabral, como adjunto dos serviços agrícolas e florestais do primeiro recenseamento agrícola da Guiné-Bissau, começou a entender o mundo e as necessidades dos camponeses. Freire fez da educação um instrumento de diálogo com os trabalhadores e entre os trabalhadores. Repensou sua filosofia a partir deste diálogo. O que faz entender a educação a partir do processo de organização do trabalho, de articulação dos movimentos, e também de estratégia de luta.

Este contato permanente com as classes trabalhadoras fez de Cabral e Freire homens extremamente pragmáticos. Embora Freire seja, às vezes, considerado idealista, ele fez escolhas e construiu percursos fundados nas práticas e voltados para as práticas.

A admiração de Freire por Cabral nos indica que a intencionalidade da sua pedagogia era e é profundamente revolucionária. Isso é algo concreto e vinculado a um processo histórico. Seria, portanto, uma limitação ler Paulo Freire sem considerar o fator de luta por transformação presente na sua ação educativa, assim como seria ler Amilcar Cabral sem reconhecer o profundo fator educativo presente na sua luta por libertação. 
1. Ver http://www.stat-guinebissau.com/ acesso em 15/6/2012.

2. Após a independência a Guiné-Bissau foi governada pelo irmão e sucessor de Amilcar Cabral, Luís Cabral, até 1980, quando este foi derrubado do poder por um golpe de estado. Desde então, o país já passou por uma guerra civil e por mais quatro golpes de estado, tendo o último ocorrido em 12 de abril de 2012. Após negociações internacionais, realizadas no âmbito da Comunidade Econômica de Estados da África Ocidental (CEDEAO), Manuel Serifo Nhamadjo foi escolhido como presidente interino da Guiné-Bissau, com um mandato de um ano, a partir de 11 de maio de 2012, e com a incumbência de realizar eleições democráticas em 2013.

3. Até hoje, no website da Presidência da República da Guiné-Bissau, existe um ícone na página principal com a biografia de Amilcar Cabral, que é considerado por muitos como o próprio "pai da nacionalidade guineense e caboverdiana": http:// www.presidencia-gw.org/amilcar_cabral. html acesso em 17/6/2012.

4. Fundado em 19 de setembro de 1956 como Partido Africano da Independência (PAI), quatro anos depois passou a se chamar Partido Africano para a Independência de Guiné e Cabo Verde (PAIGC).

5. Agostinho Neto (1922-1979), médico e poeta, fundou o Movimento Popular de Libertação de Angola (MPLA) e foi o primeiro presidente da República Popular de Angola, de 1975 a 1979. Mario Pinto de Andrade (1928-1990) foi presidente do MPLA entre 1960 e 1962. Eduardo Mondlane (1920-1969), teve uma passagem pela Universidade de Lisboa, mas se formou doutor em sociologia pela Harvard
University, e foi professor de antropologia na Syracuse University nos Estados Unidos até 1963, quando retornou a sua terra natal, Moçambique, e tornou-se fundador e primeiro presidente da Frente de Libertação de Moçambique (FRELIMO).

6. Antônio de Oliveira Salazar (1889-1970) foi presidente de Portugal entre 1932 e 1968 e instituiu em 1933 o regime fascista conhecido como "Estado Novo" ou como "salazarismo", que permanceu em vigor naquele país mesmo depois de sua morte, até 1974.

7. Amauri foi fundador da Sociedade de Intercâmbio Brasil-África (Sinba) em 1974 e foi também redator e dirigente do jornal Sinba, publicado pela entidade entre 1977 e 1980. Participou da criação do Movimento Negro Unificado (MNU) em 1978, em São Paulo, e integrou a direção do Instituto de Pesquisa das Culturas Negras (IPCN), fundado em 1975 no Rio de Janeiro, em dois momentos: no início da década de 1980 e entre 1992 e 1996, quando foi eleito presidente da entidade. O trecho citado faz parte da entrevista de história oral concedida a Verena Alberti e a Amilcar Araujo Pereira no Centro de Pesquisa e Documentação de História Contemporânea do Brasil da Fundação Getulio Vargas (CPDOC-FGV) entre 31/10/2003 e 4/11/ 2004, e está publicado no livro Histórias do movimento negro no Brasil: depoimentos ao CPDOC (Rio de Janeiro: Pallas, 2007).

8. A Conferência de Solidariedade aos Povos da África, Ásia e América Latina, conhecida como Conferência Tricontinental, foi realizada em Havana, Cuba, em janeiro de 1966, sob o impacto das vitórias das revoluções cubana e argelina e da ocupação militar dos Estados Unidos no Vietnã. Ảntes dela, haviam sido realizadas quatro Conferências de Solidariedade dos Povos 
Afro-Asiáticos, a primeira delas em Bandung, Indonésia, em 1955. Ver Sader et al. (2006) e www.wikipedia.org, acesso em 19/6/2012.

9. Após a finalização e o envio deste artigo para a Estudos Históricos, em julho de 2012 foi publicado o livro de Romão e Gadotti (2012) sobre o tema.

10. O Conselho congrega mais de 340 igrejas cristãs - ortodoxas, anglicanas, batistas, luteranas, metodistas, reformadas - difundidas entre África, Ásia, Caribe, América Latina, Oriente Médio e Pacífico e está comprometido mundialmente com projetos de desenvolvimento ligados à alfabetização, ao problema da fome e da sede, às mudanças climáticas e à defesa do meio ambiente, remetendo a uma mensagem evangélica em contraposição aos métodos de colonização impostos pela globalização econômica.

11. Refere-se ao discurso de Amilcar Cabral na Conferência Tricontinetal em Havana, Cuba, em 1966, já citada.

\section{Referências bibliográficas}

ALBERTI, Verena \& PEREIRA, Amilcar Araujo (orgs.) Histórias do movimento negro no Brasil. Rio de Janeiro: Pallas/ CPDOC/ FGV, 2007.

ANAIS do Simpósio Internacional Amilcar Cabral. Praia: Cabo Verde, 1983.

APOLUCENO DE OLIVEIRA, Ines. Leituras freireanas sobre a educação. São Paulo: Editora Unesp, 2003.

CABRAL, Amilcar. Return to the source: selected speeches of Amilcar Cabral. New York: Monthly Review Press, 1973.
12. Primeiro Caderno de Cultura Popular: A Luta Continua, A Vitória é Nossa (República Democrática de São Tomé e Príncipe, Ministério da Educação Nacional e Desporto, Departamento da Educação de Adultos e Alfabetização, 1980); Terceiro Caderno de Cultura Popular: A Luta Continua, Nosso Povo, Nossa Terra, Trabalho, Produção e Conta (República Democrática de São Tomé e Príncipe, Ministério da Educação Nacional e Desportos, Comissão Nacional Coordenadora dos Círculos de Cultura Popular, 1978); Quarto Caderno de Educação Popular: A Luta Continua, Nosso Povo, Nossa Terra, Trabalho, Produção, Cultura e Saúde (República Democrática de São Tomé e Príncipe, Ministério da Saúde, 1979); A Luta Continua: Praticar Para Aprender, Caderno de Exercícios (República Democrática de São Tomé e Príncipe, Ministério da Educação Nacional e Desporto, Departamento de Educação e Alfabetização de Adultos, 1980).

\footnotetext{
- Guiné-Bissau, nação africana forjada na luta. Lisboa: Nova Aurora, 1974a.
} PAIGC: Unida e Luta. Lisboa: Nova Aurora, 1974b.

FUNDAÇÃO MARIO SOARES. Amílcar Cabral: sou um simples africano... Lisboa: Fundação Mario Soares, 2000.

FREIRE, Ana Maria (org.). Pedagogia da tolerância. São Paulo: Editora Unesp, 2005.

FREIRE, Paulo. Educação como prática da liberdade. [1957]. $28^{\mathrm{a}}$ ed. Rio de Janeiro: Paz e Terra, 2005. 
- Pedagogia do oprimido. [1970] $40^{\mathrm{a}}$ ed. São Paulo: Paz e Terra, 2006.

- Cartas à Guiné-Bissau: registros de uma experiência em progresso. [1977] $4^{\mathrm{a}}$ ed. Rio de Janeiro: Paz e Terra, 1984.

\& FAUNDEZ, Antonio. Por uma pedagogia da pergunta. $6^{\mathrm{a}}$ ed. São Paulo: Paz e Terra, 2007.

\& GUIMARÃES, Sergio. $A$ África ensinando a gente. Angola, Guiné-Bissau, São Tomé e Príncipe. São Paulo: Paz e Terra, 2002.

GADOTTI, Moacir. Paulo Freire na África: notas sobre o encontro da pedagogia freiriana com a práxis política de Amílcar Cabral, Forum Paulo Freire, Cabo Verde, 2010. http://siteantigo.paulofreire.org./ Crpf/LegadoPFArtigos.

IDAC (Instituto de Ação Cultural). GuinéBissau '79. Learning by living and doing. Geneva (Suíça), 1979.

LAINS, Pedro. Causas do colonialismo português em África,1822-1975. In: Análise Social, vol. 33, Revista da Universidade de Lisboa, 1998.

LOPES, Carlos. Amilcar Cabral: uma inspiração para os dias de hoje. In: LOPES, Carlos (org.). Desafios contemporâneos $d a$ África: o legado de Amilcar Cabral. São Paulo: Editora Unesp, 2012.

MARX, Karl \& ENGELS, Friedrich. $A$ ideologia alemã (Feuerbach). São Paulo: Hucitech, 1991.
MEMMI, Albert. Retrato do colonizado precedido do retrato do colonizador. [1957] Rio de Janeiro: Civilização Brasileira, 2007.

MENDY, Peter. Amilcar Cabral e a libertação da Guiné-Bissau: contexto, desafios e lições para uma liderança africana efetiva. In: LOPES, Carlos (org.). Desafios contemporâneos da África: o legado de Amilcar Cabral. São Paulo: Editora Unesp, 2012.

RATO, Maria Helena da Cunha. O colonialismo português, factor de subdesenvolvimento nacional. In: Análise Social, vol. 19, Revista da Universidade de Lisboa, 1983.

ROMÃO, José Estáquio \& GADOTTI, Moacir. Paulo Freire e Amílcar Cabral: a descolonização das mentes. São Paulo: Instituto Paulo Freire, 2012.

SADER, Emir et al. (org.). Enciclopédia contemporânea da América Latina e do Caribe. Rio de Janeiro: Uerj; São Paulo: Boitempo, 2006.

SCOCUGLIA, Afonso Celso. A influência de Amilcar Cabral e do trabalho na África na construção da práxis de Paulo Freire. VII Forum Paulo Freire, 2010. http://site antigo.paulofreire.org/Crpf/LegadoPFArti gos.

VITTORIA, Paolo. Narrando Paulo Freire. Por uma pedagogia do diálogo. Rio de Janeiro: Editora UFRJ, 2011.

\section{Resumo}

O objetivo deste artigo é apresentar aspectos da trajetória política de Amilcar Cabral no contexto da luta pelar libertação da Guiné-Bissau entre as décadas de 1950 e 1970, para então analisar como o educador Paulo Freire, 
a partir de sua experiência de alfabetização na Guiné Bissau em 1974, se inspirou na ação política e na produção teórica de Cabral.

Através dessa reconstrução histórica pretendemos promover reflexões sobre o colonialismo e, como diria Amilcar Cabral, sobre a "luta de libertação como um fator de cultura".

Palavras-chave: Amilcar Cabral; Paulo Freire; Guiné-Bissau; colonialismo; lutas de independência.

\section{Abstract}

The aim of this article is to present aspects of the political career of Amilcar Cabral in the context of the struggle for liberation in Guinea-Bissau between the decades of 1950 and 1970, and then analyse how the Brazilian educator Paulo Freire, from his experience of literacy in Guinea-Bissau in 1974, was inspired by Cabral's political action and theoretical production. Through this historical reconstruction we intend to promote reflections on colonialism and, as Amilcar Cabral would say, on "liberation struggle as a factor of culture".

Key-words: Amilcar Cabral; Paulo Freire; Guinea-Bissau; colonialism; liberation struggle.

\section{Résumé}

Cet article présente des aspects de l'itinéraire politique d'Amilcar Cabral dans le contexte de la lutte pour la libération de Guinée-Bissau entre les années 1950 et 1970, pour finalement analyser comment l'éducateur Paulo Freire, à partir de son expérience d'alphabétisation en Guinée Bissau, s'est inspiré de l'action politique et de la production théorique de Cabral. Par cette reconstruction historique, nous avons l'intention de susciter des réflexions sur le colonialisme et, comme dirait Amilcar Cabral, sur la lutte de "libération comme facteur de culture".

Mots-clés: Amilcar Cabral; Paulo Freire; Guinée-Bissau; colonialisme; luttes d'independence. 